\title{
Removal behavior and output quality for laser chemical machining of tool steels
}

\author{
Hamza Messaoudi ${ }^{1, *}$, Merlin Mikulewitsch ${ }^{2}$, Daniel Brand ${ }^{1}$, Axel von Freyberg ${ }^{2}$, and Andreas Fischer ${ }^{2}$ \\ ${ }^{1}$ BIAS - Bremer Institut für angewandte Strahltechnik, Bremen, Germany \\ ${ }^{2}$ University of Bremen, BIMAQ - Bremen Institute for Metrology, Automation and Quality Science, Bremen, Germany
}

Received: 15 December 2018 / Accepted: 14 May 2019

\begin{abstract}
Laser chemical machining represents a promising technology for manufacturing metallic micro parts. It is usually based on the selective thermal activation of electrochemical material dissolution of self-passivating metals in an electrolyte environment. Prior to widespread industrial acceptance, its machining quality needs to be classified within the subtractive machining processes and the range of machinable materials needs to be expanded. For this purpose, line and square cavities with dimensions $\leq 300 \mu \mathrm{m}$ are machined into high speed steel HS10-4-3-10 in a $\mathrm{H}_{3} \mathrm{PO}_{4}$-environment and compared to those of the self-passivating cobalt-chrome alloy Stellite 21. As a result, the laser-induced removal velocities in HS10-4-3-10 amount to $50 \mu \mathrm{m} / \mathrm{s}$. These are two orders of magnitudes higher than the background etching $(2 \mathrm{~nm} / \mathrm{s}$ at room temperature) and three times higher than those obtained in Stellite $21(12 \mu \mathrm{m} / \mathrm{s})$. However, the microscopic and spectroscopic analyses of both materials reveal a high shape accuracy with edge radii from 10 to $20 \mu \mathrm{m}$, a surface roughness down to $0.8 \mu \mathrm{m}$ and a negligible microstructural impact. Despite lower removal rates and higher surface roughness, laser chemical machining provides higher dimensional accuracy in comparison with micro milling and shows its suitability for micro machining of structures $<200 \mu \mathrm{m}$.
\end{abstract}

Keywords: Micro machining / laser chemical machining / passivation / quality / roughness

\section{Introduction}

Manufacturing of metallic parts by micro forming is a key approach to meet the ever-increasing demand for micro mechanical and micro electrical components, required for, e.g., consumer products or biomedical devices. Forming dies applied to the manufacture of those components usually exhibit geometrical features of several tenths of micrometers with tolerances in the sub-micrometer range [1]. Therefore, the achievable dimensional accuracy as well as the resulting surface roughness represent crucial figures of merit for micro forming processes [2].

Moreover, tool materials for forming processes require appropriate ductility combined with high hardness and wear resistance [3]. These include mono crystals (e.g. sapphire) as well as ceramic materials (e.g. alumina, zirconia, etc.) and cemented carbides (e.g. tungsten or titanium carbide), which are characterized by complex, time- and cost-intensive production procedures. In addition, metallic alloys such as iron-,

\footnotetext{
* e-mail: messaoudi@bias.de
}

nickel- and cobalt-based alloys represent widely used alternative materials. However, the manufacture of micro forming tools from the mentioned alloys is still challenging due to additionally occurring size effects in the microscale [4].

Using conventional machining techniques like milling and turning, which are based on mechanical material removal, the hardness of applied tools should significantly exceed that of the machined material. Thereby, the induced thermomechanical loads can induce additional residual stresses and change the micro structure in the surface-near layers. Thus, the chemical inertia as well the stability could be limited [5]. For forming dies exhibiting geometries or features smaller than $1 \mathrm{~mm}$ micro milling is widely used, especially in mold manufacturing, due to its high removal rates (some $\mathrm{mm}^{3} / \mathrm{min}$ ) and its excellent surface finish [6]. To ensure high surface quality, fine grained tool steels with dispersed carbides are used. Thus, a mean roughness value $R a$ of some $10 \mathrm{~nm}$ can be realized. Nevertheless, micro milling is limited regarding the dimensional accuracy and the surface finish; especially when tools of $\leq 0.2 \mathrm{~mm}$ in diameter are applied. This can be explained by the incidence of ploughing effects and feed marks [6]. 
Alternatively, hard materials can be manufactured using non-conventional machining. Among others this includes laser machining and electrochemical machining (ECM) [7]. Laser machining, based on material ablation, is characterized by an increased machining precision and quality with shorter laser pulses. However, as the removal rate and the processing quality are reciprocal, the economic use of ultrashort pulsed lasers is still inefficient due to the high procurement costs and the low removal rates (typically $10^{-3} \mathrm{~mm}^{3} / \mathrm{min}$ ) [8]. Besides that, ECM is characterized by its smooth and low-cost machining. Due to the purely chemical removal the micro structure properties at the workpiece surface remain unaffected. This makes ECM very suitable for the manufacture of temperature sensitive materials such as NiTi-alloys. Nevertheless, in the microscale, the size of achievable structures is limited by the size of the electrode, which itself has to be manufactured in advance [9].

One process that unifies the advantages of laser and electrochemical machining is the laser chemical machining (LCM). Within this process, the laser beam heats up the workpiece, which is immersed in a continuously pumped electrolyte [10]. Depending on the laser parameters, such as the laser power and spot diameter, the induced thermal heating of the workpiece surface can shift the electrochemical potential to the transpassive region, in which the anodic material dissolution is enhanced. This laseractivated chemical dissolution was observed for different self-passivating metals e.g. stainless steel and titanium alloys [11]. In comparison, materials that do not form a passivation layer when immersed in the electrolyte, are assumed to be non-machinable and thereby are not studied systematically.

Within suitable process windows, laser-induced material removal occurs without micro structural changes, significant heat affected zones or recast formation. The removal quality was found to be the main advantage of the LCM process in comparison to the short-pulsed laser machining, which often results in micro-cracks and distortion effects. Due to the small applied laser power densities $\left(<100 \mathrm{~kW} / \mathrm{cm}^{2}\right.$ for laser focus diameters below $100 \mu \mathrm{m})$, compared to those in the $\mathrm{GW} / \mathrm{cm}^{2}$ range for laser ablation processes, phase changes and material melting are avoided in LCM [12]. However, the LCM process is marked by its high sensitivity against small parameter variations due to the limited process window and by the low removal rates (up to $10^{-3} \mathrm{~mm}^{3} / \mathrm{min}$ ) [12]. Further, previous works have shown that the surface roughness depends strongly on the applied scan velocity. The areal arithmetical mean roughness $S a$ at the ground of micro cavities machined with velocities $<20 \mu \mathrm{m} / \mathrm{s}$ into the chrome-cobalt alloy Stellite 21 was found to be $>2 \mu \mathrm{m}$ [13,14], whereby at velocities $>1 \mathrm{~mm} / \mathrm{s}$ a polishing effect was demonstrated in titanium resulting in Sa-values down to $0.1 \mu \mathrm{m}$ [15]. Hence, the combination of low and high feed velocities could increase the surface quality of LCM-machined micro parts.

Pursuing a strategy that comprises roughing and finishing steps, the aim of this work is to investigate the LCM machinability of metallic materials without selfpassivation property and to characterize their removal behavior and quality regarding the dimensional accuracy,
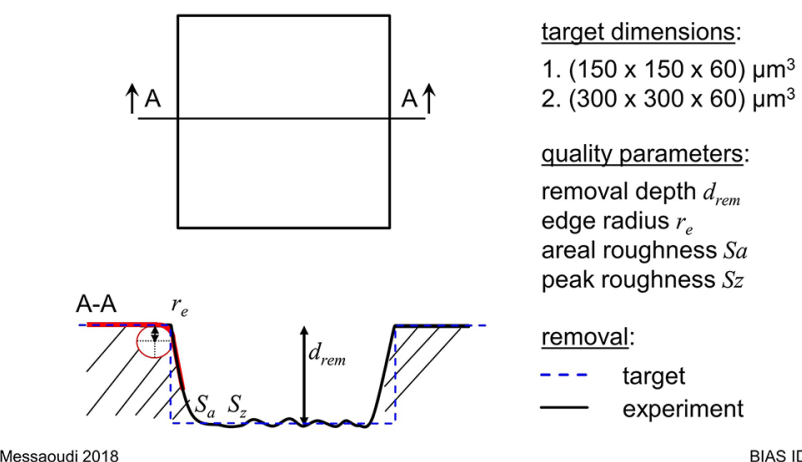

Fig. 1. Schematic illustration of the cavity geometry as well as the investigated quality parameters.

the surface roughness and the impact on the material's micro structure. In addition, the LCM machining quality is compared with micro milling as a reference micro machining technique.

The considered machining task, the experimental plan as well as the analysis methods are introduced in Section 2. Section 3 presents in detail the laser chemical removal behavior of the cobalt-chrome alloy Stellite 21 (selfpassivating material) and the high speed steel HS10-4-3-10 (non self-passivating material) in a 5 molar $\mathrm{H}_{3} \mathrm{PO}_{4^{-}}$ environment. First, the influence of the material passivation property within the used electrolyte is investigated based on single line cavities in dependence of laser power and feed velocity. Second, the influence of lateral overlap on the removal and surface quality is determined in dependence of laser power, feed velocity and scan repetitions. Following that, square micro cavities exhibiting side lengths between $100 \mu \mathrm{m}$ and $400 \mu \mathrm{m}$ and a depth of $60 \mu \mathrm{m}$, representing forming cavities of micro cold forging dies, are machined into both materials. The geometrical features, the surface roughness as well as the micro structural impact - regarding changes in the chemical composition - on the surface-near layers are investigated in both materials. Furthermore, the machining results are discussed in Section 4 with regard to the material passivation behavior and compared with those of micro milling. Finally, Section 5 closes the paper with a conclusion.

\section{Methodology}

\subsection{Machining task}

With the aim to characterize the LCM processing quality in tool steels of different passivation behaviors within the applied electrolyte, micro cavities that are of interest for micro cold forging and embossing, were machined. On the surface of eroded samples with a thickness of $5 \mathrm{~mm}$, square micro cavities with side lengths between $100 \mu \mathrm{m}$ and $400 \mu \mathrm{m}$ and depths of $60 \mu \mathrm{m}$ were laser chemically machined. Figure 1 shows the targeted dimensions as well the quality parameters to be investigated. The characterization includes geometrical properties (side length, edge radius and cavity depth), surface roughness and chemical 
properties that can indicate possible micro structural impact related to the machining process.

\subsection{Materials and electrolyte}

An aqueous phosphoric acid solution with a concentration of $28.7 \%(5 \mathrm{~mol} / \mathrm{l})$ was used as electrolyte solution. Moreover, the cast chrome-cobalt alloy Stellite 21 from "Deloro Wear Solutions GmbH" and the high speed steel HS10-4-3-10 from "Hoffmann group" were used as sample materials that are widely used in manufacturing micro forming and cutting tools. Stellite 21 with the chemical composition $(>60 \% \mathrm{Co}, 27 \% \mathrm{Cr}, 5.5 \% \mathrm{Mo}, 2.5 \% \mathrm{Ni}$ and $1.5 \% \mathrm{Fe}$ ) has a hardness of $27 \mathrm{HRC}$ to $40 \mathrm{HRC}$ and possesses a self-passivation property within the used electrolyte solution. A thin oxide layer is built up and protects the material from corrosion. In contrast, HS10-43-10 (10\% Co, $4 \%$ Cr, 3.6\% Mo, 3.2\% C and 9.5\% W) has a hardness of $60 \mathrm{HRC}$ to $67 \mathrm{HRC}$ and does not form a selfpassivation layer, so that a material dissolution starts immediately within the used electrolyte environment. The background etching velocities of HS10-4-3-10 in a 5 molar phosphoric acid environment were determined in [16] based on measured weight losses following the DIN 50905. While $2 \mathrm{~nm} / \mathrm{s}$ were determined at $20^{\circ} \mathrm{C}$, the background etching velocity at $60{ }^{\circ} \mathrm{C}$ amounted to up to $135 \mathrm{~nm} / \mathrm{s}$. Due to the limited heating area (some $100 \mu \mathrm{m}^{2}$ ) in LCM, most regions (with temperatures close to $20^{\circ} \mathrm{C}$ ) will not exceed a background etching rate of $2 \mathrm{~nm} / \mathrm{s}$.

\subsection{Experimental investigation}

The cw-fiber laser TruFiber 300 (from Trumpf) was applied as a laser source. Its Gaussian laser radiation of $1080 \mathrm{~nm}$ is first collimated to a beam diameter of $8 \mathrm{~mm}$ and then focussed using a high aperture lens system (focal length of $50 \mathrm{~mm}$ ). With this system, the focal spot size $d_{\text {spot }}$ amounts to $25 \mu \mathrm{m}$. The electrolyte, a 5 molar ( $28.7 \%$ vol.) phosphoric acid solution $\left(\mathrm{H}_{3} \mathrm{PO}_{4}\right)$, is pumped through a $2 \mathrm{~mm}$ wide nozzle that is arranged coaxially to the laser beam with a velocity $v_{\text {flow }}$ of $3.14 \mathrm{~m} / \mathrm{s}$. The propagation of the laser beam through the electrolyte affects the power density due to an experimentally identified transmission coefficient $\tau_{E}$ of 0.45 . More details about the setup can be found in [17].

In order to identify the influence of the relevant process parameters on the removal quality, a systematic investigation was performed in both materials. For this purpose, the laser-induced surface temperatures were calculated following a Green-function based thermal modelling in order to reduce the experimental expenditure [18]. The thermal impact was restricted to surface temperatures below $400^{\circ} \mathrm{C}$.

Based on the predicted surface temperatures, two lines of $1 \mathrm{~mm}$ in length were first machined for each parameter combination depending on laser power and feed velocity. Second, suitable laser and feed parameters were selected to determine the influence of the degree of overlap $\mathrm{O}_{\%}$ or the lateral hatching $d_{\text {overlap, }}$ respectively. These quantities depend on the width of single removal line $w_{\text {rem }}$ and can be
Table 1. Varied process parameters for the laser chemical manufacture of Stellite 21 and HS10-4-3-10.

\begin{tabular}{llll}
\hline Parameter & Unit & \multicolumn{2}{c}{ LCM } \\
\cline { 3 - 4 } & & Roughing & Finishing \\
\hline Laser spot $d_{\text {spot }}$ & $\mu \mathrm{m}$ & 25 & 25 \\
Laser power $P_{L} \times \tau_{E}$ & $\mathrm{~W}$ & $0.4 \ldots 1.8$ & $0.3 \ldots 0.6$ \\
Peak temperature $T_{(x=0)}$ & ${ }^{\circ} \mathrm{C}$ & $100 \ldots 400$ & $100 \ldots 200$ \\
Feed velocity $v_{\text {feed }}$ & $\mu \mathrm{m} / \mathrm{s}$ & $5 \ldots 100$ & $50 \ldots 1000$ \\
Scan repetitions $n_{\text {scan }}$ & - & 1,2 & $10,20,30$ \\
Degree of overlap $O_{\%}$ & $\%$ & $0 \ldots 90$ & $0 \ldots 90$ \\
Lateral hatching $d_{\text {overlap }}$ & $\mu \mathrm{m}$ & var. & var. \\
\hline
\end{tabular}

defined as follows:

$$
O_{\%}=\left(1-\frac{d_{\text {overlap }}}{w_{\text {rem }}}\right) \times 100 .
$$

Following, the square micro cavities were machined with a strategy that is similar to that used in micro milling. As a first step, a roughing is applied to achieve the aimed removal depth. In a following step, laser chemical finishing is applied to improve the surface quality. It has to be mentioned that a bidirectional scanning with a $90^{\circ}$ rotation after every scan repetition has been applied. Finally three cavities of dimensions $(150 \times 150 \times 60) \mu^{3}$ and $(300 \times 300 \times 60) \mu^{3}$ were manufactured from the two materials in order to be characterized regarding their manufacturing quality and to identify possible influences related to the material passivation behavior. Table 1 illustrates the main parameter variation investigated within this work.

\subsection{Determination of manufacturing quality}

To examine the material-dependent manufacturing quality geometrical properties such as removal depth $d_{\text {rem }}$, edge radius $r_{e}$ and shape accuracy were recorded and characterized using a laser scanning confocal microscope (VHX970Keyence) and a scanning electron microscope (SEM, EVO M10-Zeiss).

In order to enable the comparison with other subtractive machining processes such as electrochemical machining $(\mathrm{ECM})$ the removal velocity $v_{\text {rem }}$ was determined as follows:

$$
v_{\mathrm{rem}}=d_{\mathrm{rem}} \times \frac{d_{\mathrm{spot}}}{v_{\mathrm{rem}}} .
$$

For the determination of the edge radius, a $2 \mathrm{D}$ holistic approximation was used [19]. Based on an algorithm that uses continuous transitions and an automatic separation of the composite geometries, measured points of a $2 \mathrm{D}$ profile line (cross section of the cavity) are assigned dynamically to the individual control geometries (line-circle-line) [20]. The approximation minimizes the orthogonal point 


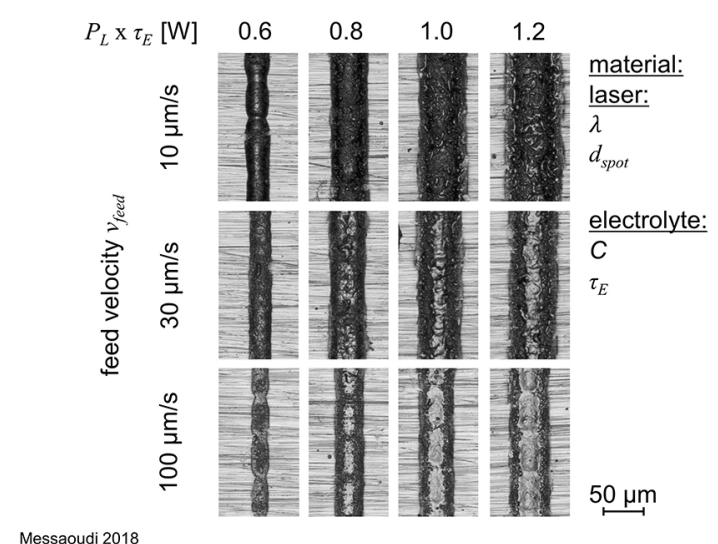

Fig. 2. Microscopic images showing the quality of the laser chemical removal in Stellite 21 in dependence of the applied laser power $P_{L} \times \tau_{E}$ and feed velocity $v_{\text {feed }}$.

distances to these standard geometries according to the L2norm and iteratively improves the parameters of the composite profiles to fit the measured profile [21]. In this work, the mean upper edge radius $r_{e}$ of each cavity was determined by approximating 20 profile lines spread over the cavity, half horizontally and half vertically aligned. The profile lines, for which the holistic approximation did not converge, due to e.g. excessive burrs along the edges, were removed from consideration for determining the mean edge radius. In addition, the removal width and depth of the removal cavities were evaluated based on automated Matlab routine, that determines the mean values as well the standard deviations of minimum 300 cross-sectional profiles [22]. Further, the areal surface roughness Sa and the peak roughness $\mathrm{Sz}$ were determined at the cavity ground following the ISO 25178.

To identify the influence of the manufacturing method on the micro structure, the SEM-records were in addition complemented by an energy dispersive spectroscopic (EDS) analysis to show the chemical composition on selected regions within the cavities.

\section{Results}

\subsection{Laser chemical removal behavior}

\subsubsection{Single line removal cavities}

\subsubsection{Removal in Stellite 21}

Figure 2 shows the microscopic images of the removal cavities in Stellite 21 in dependence of the laser power and feed velocity. A detectable material removal has been observed starting at a laser power $P_{L} \times \tau_{E}$ of $0.6 \mathrm{~W}$. With increasing laser power, the removal cavity was widened and deepened. Moreover, it was observed that a disturbancefree removal, in which the cavity cross-section is characterized by a bell-like profile, was ensured up to laser powers between $0.8 \mathrm{~W}$ and $0.9 \mathrm{~W}$. By further increasing the laser power the removal has become more inhomogeneous, as the disturbances at the centre of the cavities show.
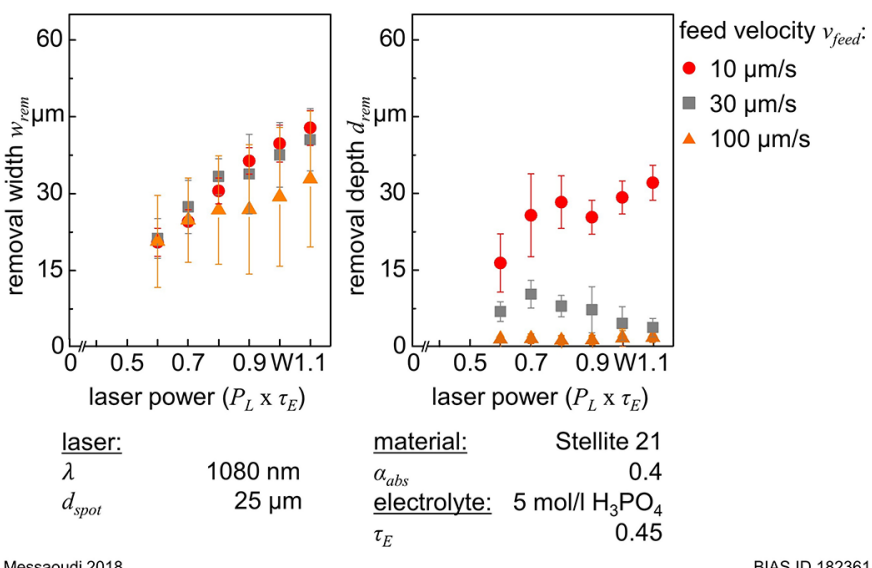

Messaoudi 2018

Fig. 3. Width and depth of the resulting LCM cavities in Stellite 21 in dependence of the applied laser power and the feed velocity.
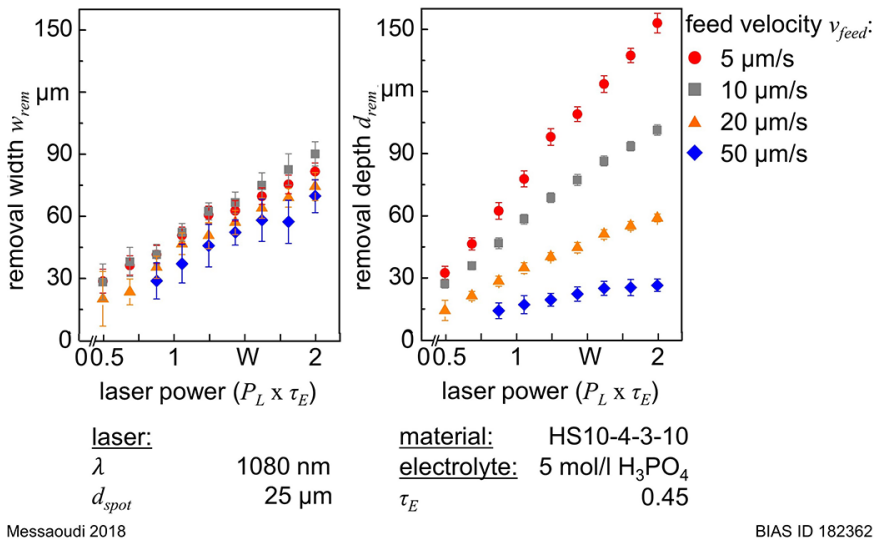

Fig. 4. Width and depth of the resulting LCM cavities in HS104-3-10 in dependence of the applied laser power and the feed velocity.

The quantitative characterization of the resulting removal width $w_{\text {rem }}$ and depth $d_{\text {rem }}$ in Stellite 21 is illustrated in Figure 3. Within the disturbance-free removal regime (for laser powers between $0.6 \mathrm{~W}$ and $0.8 \mathrm{~W})$ it is observed that the removal width $w_{\text {rem }}$ increases nearly linearly from $17 \mu \mathrm{m}$ to $40 \mu \mathrm{m}$ with the laser power. In comparison to the laser power, the influence of the feed velocity on the removal width is smaller. Moreover, the removal depth $d_{\text {rem }}$ increases linearly with the laser power. Once removal disturbances occur (laser powers between $0.8 \mathrm{~W}$ and $0.9 \mathrm{~W}$ ), a clear drop in removal depth is observed. As discussed in [18], the occurrence of removal disturbances is caused by the adherence of boiling-related gas bubbles. Moreover, the removal depth decreases with rising feed velocity.

\subsubsection{Removal in HS10-4-3-10}

As Figure 4 shows, the resulting removal width $w_{\text {rem }}$ and depth $d_{\text {rem }}$ increased linearly with the laser power. However, their rise declined with increasing feed velocity. 


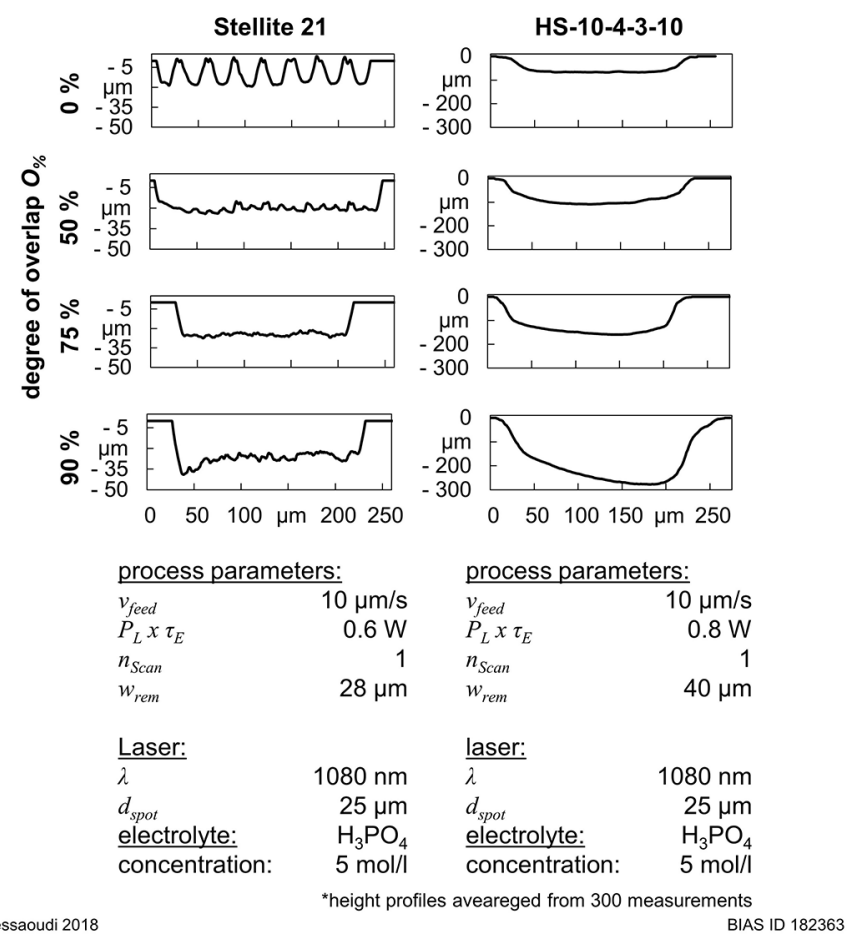

Fig. 5. Influence of the lateral overlapping on the large-area cross-sectional LCM removal profile in Stellite 21 and HS10-4-310.

Between $0.4 \mathrm{~W}$ and $2 \mathrm{~W}$, the depth $d_{\text {rem }}$ increased from around $20 \mu \mathrm{m}$ to $155 \mu \mathrm{m}$ with $v_{\text {feed }}=5 \mu \mathrm{m} / \mathrm{s}$, while only to $60 \mu \mathrm{m}$ with $v_{\text {feed }}=20 \mu \mathrm{m} / \mathrm{s}$. At $\left(P_{L} \times \tau_{E}\right)=0.9 \mathrm{~W}$ the width $w_{\text {rem }}$ decreased from $42 \mu \mathrm{m}$ at $v_{\text {feed }}=10 \mu \mathrm{m} / \mathrm{s}$ to $29 \mu \mathrm{m}$ at $v_{\text {feed }}=50 \mu \mathrm{m} / \mathrm{s}$.

\subsubsection{Influence of lateral overlapping in large-area removal}

For an efficient large-area material removal, the suitable lateral overlapping has been determined based on removal width $w_{\text {rem }}$ of a single line cavity. Figure 5 summarizes the influence of lateral overlap from $0 \%$ to $90 \%$ on the crosssectional removal profile in Stellite 21 and HS10-4-3-10. The applied laser powers were $0.6 \mathrm{~W}$ for Stellite 21 and $0.8 \mathrm{~W}$ for HS10-4-3-10, while the scan velocity of $10 \mu \mathrm{m} / \mathrm{s}$ were selected for both materials.

In Stellite 21, the waviness at the cavity ground was reduced with increased lateral overlapping. The best results concerning flatness and homogeneous removal were obtained at a lateral overlap of $75 \%$. A further increase up to $90 \%$ results in a $\mathrm{W}$-like cross-sectional profile, which is characterized by an intensified material removal at the cavity borders. In contrast, HS10-4-3-10 shows a different behavior. Due to the background etching, a homogeneous removal with low waviness was obtained at a $0 \%$ degree of overlap. The flatness of the cavity ground was reduced when decreasing the lateral hatching $d_{\text {overlap }}$. Considering the conditions of a disturbance-free removal, it was observed that the targeted cavity depth of $60 \mu \mathrm{m}$ can be achieved with a single scan in HS10-4-3-10, while 2 scan repetitions are required in Stellite 21.
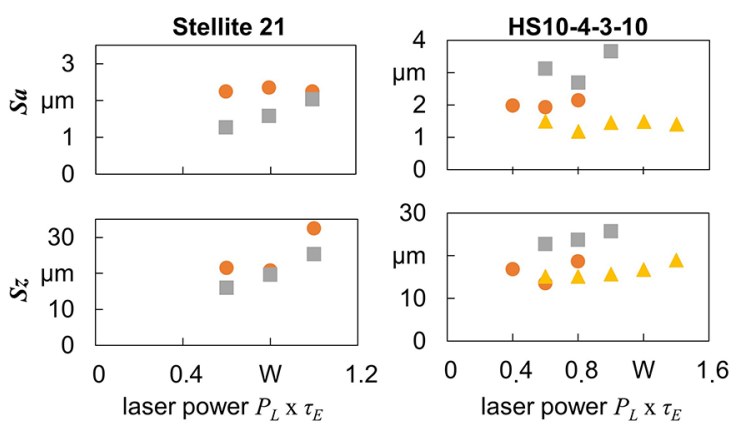

feed velocity $v_{\text {feed }}$ : $\quad 5 \mu \mathrm{m} / \mathrm{s}$

- $10 \mu \mathrm{m} / \mathrm{s} \triangle 20 \mu \mathrm{m} / \mathrm{s}$
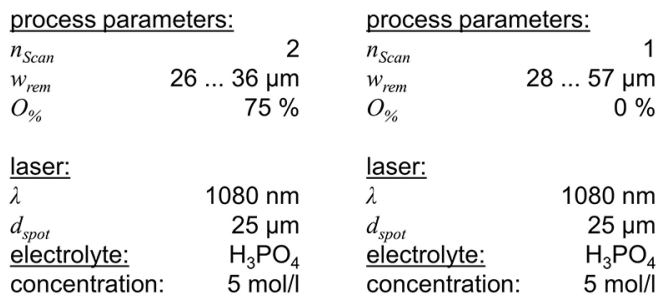

$\begin{array}{lr}\text { laser: } & \\ \lambda & 1080 \mathrm{~nm} \\ d_{\text {spot }} & 25 \mu \mathrm{m} \\ \text { electrolyte: } & \mathrm{H}_{3} \mathrm{PO}_{4} \\ \text { concentration: } & 5 \mathrm{~mol} / \mathrm{l}\end{array}$

Messaoudi 2018

BIAS ID 182364

Fig. 6. Determined arithmetical mean roughness $S a$ and peak roughness $S z$ after laser chemical finishing of Stellite 21 and HS10-4-3-10 in a 5 molar phosphoric acid environment with different combinations of laser power, feed velocity and scan repetitions.

Moreover, the measured surface roughness values $S a$ and $S z$, shown in Figure 6, revealed that a further improvement of the surface quality is necessary. The arithmetical mean roughness $S a$ was found to lay between $1.4 \mu \mathrm{m}$ and $2.2 \mu \mathrm{m}$ in Stellite 21 and between $1.2 \mu \mathrm{m}$ and $3.7 \mu \mathrm{m}$ in HS10-4-3-10. In contrast, the maximum height $S z$ ranged from $15 \mu \mathrm{m}$ to $35 \mu \mathrm{m}$ in both materials.

\subsubsection{Laser chemical finishing}

To improve the surface quality on the ground of the cavities, a finishing step was applied. This was based on low laser powers $\left(\left(P_{L} \times \tau_{E}\right) \leq 0.5 \mathrm{~W}\right)$ and increased feed velocities $\left(v_{\text {feed }} \geq 50 \mu \mathrm{m} / \mathrm{s}\right)$. The energy input per time unit within this parameter range could not result in a detectable removal after a single scan. An additional removal $(>1 \mu \mathrm{m})$ is only obtained after several scan repetitions. For that reason, the lateral overlapping during the finishing was varied by assuming a removal width of $25 \mu \mathrm{m}$ (equal to the laser spot size) for all combinations. The finishing step was performed on roughened cavities that were characterized by an average $S a$-value of $1.9 \mu \mathrm{m}$ and $1.5 \mu \mathrm{m}$ and an average $S z$-value of $18 \mu \mathrm{m}$ and $15 \mu \mathrm{m}$ in Stellite 21 and HS10-4-3-10, respectively.

Figure 7 shows the influence of laser power, feed velocity and number of scans on the surface quality of Stellite 21. A significant reduction of the surface roughness is obtained with $n_{\text {scan }}>20$. The arithmetical mean roughness $S a$ was reduced from $1.9 \mu \mathrm{m}$ down to $1.0 \mu \mathrm{m}$. In contrast, the peak roughness was increased with almost all parameter combinations from $13 \mu \mathrm{m}$ in average to 
Table 2. Summary of the selected parameters for the laser chemical manufacture of the micro cavities [17].

\begin{tabular}{llllll}
\hline & $P_{L} \times \tau_{E}[\mathrm{~W}]$ & $v_{\text {scan }}[\mu \mathrm{m} / \mathrm{s}]$ & $d_{\text {overlap }}[\mu \mathrm{m}]$ & $n_{\text {scan }}[-]$ & $t_{\text {process }}[\mathrm{min}]$ \\
\hline LCM roughing & 0.6 & 10 & 7.00 & 2 & $12: 30^{*}$ \\
LCM finishing & 0.3 & 50 & 6.25 & 30 & $50: 00^{* *}$ \\
& & & & & $37: 30^{*}$ \\
\hline
\end{tabular}

* Cavity dimensions of $(150 \times 150 \times 60) \mu^{3}{ }^{3}$.

** Cavity dimensions of $(300 \times 300 \times 60) \mu \mathrm{m}^{3}$.

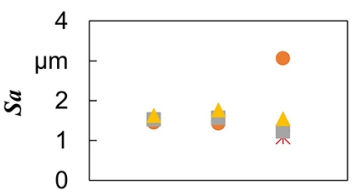

feed velocity $v_{\text {feed }}$ :
* $50 \mu \mathrm{m} / \mathrm{s} ; 0.3 \mathrm{~W}$
$50 \mu \mathrm{m} / \mathrm{s} ; 0.5 \mathrm{~W}$
$500 \mu \mathrm{m} / \mathrm{s} ; 0.5 \mathrm{~W}$
$1000 \mu \mathrm{m} / \mathrm{s} ; 0.5 \mathrm{~W}$

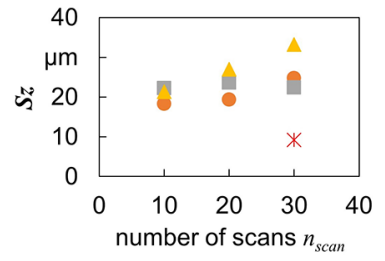

overlapping:

$b_{\text {rem (assumed) }}$

$\mathrm{O}_{\%}$

$d_{\text {overlap }}$

initial surface:

$S a$

$S z$

$1080 \mathrm{~nm}$

material: $\quad$ Stellite 21

electrolyte: $\quad \mathrm{H}_{3} \mathrm{PO}_{4}$

concentration: $\quad 5 \mathrm{~mol} / \mathrm{l}$

BIAS ID 182365

Fig. 7. Influence of different applied finishing combinations (laser power, scan repetitions and feed velocity) on the arithmetic mean roughness $S a$ and peak roughness $S z$.

values ranging between $17 \mu \mathrm{m}$ and $25 \mu \mathrm{m}$. However, with the combination of $n_{\text {scan }}=30, P_{L} \times \tau_{E}=0.3 \mathrm{~W}$ and $v_{\text {feed }}=$ $50 \mu \mathrm{m} / \mathrm{s}$, the maximum height $S z$ was reduced to $8 \mu \mathrm{m}$. In comparison to Stellite 21, the LCM finishing in HS10-4-310 was not successful, as the surface roughness was increased to values $>2 \mu \mathrm{m}$ for $S a$ and $>20 \mu \mathrm{m}$ for $S z$. Moreover, an additional removal depth of $<20 \mu \mathrm{m}$ has been measured.

\subsection{Manufacturing of square cavities in Stellite $\mathbf{2 1}$}

\subsubsection{Machining strategy}

Table 2 summarizes the selected processing parameters for the manufacture of the square cavities in Stellite 21. The cavities were machined based first on a roughing step to achieve the target removal depth and second on a finishing step with the aim to improve the surface quality.

\subsubsection{Geometrical properties}

Figure 8 shows exemplarily SEM images of laser chemically roughened and finished micro cavities with the targeted dimensions of $(300 \times 300 \times 60) \mu^{3}$. The LCM roughing results in grossly achieving the cavity dimensions, while the LCM finishing provides a final contouring and a surface smoothing, especially at the cavity ground.
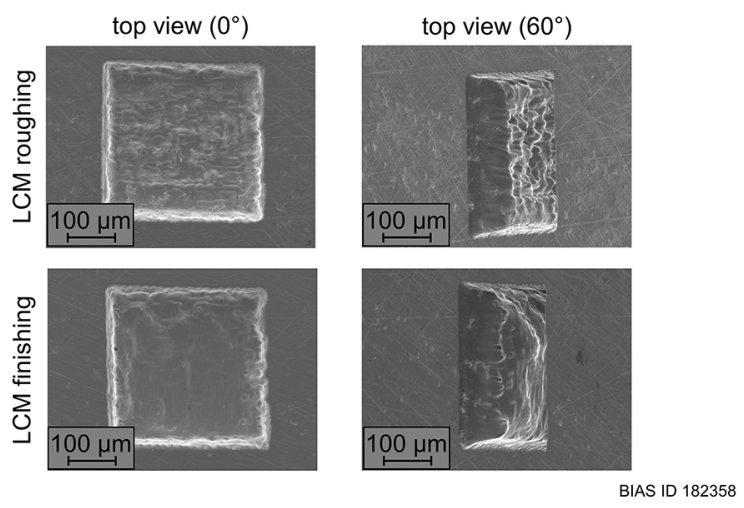

Messaoudi 2018 (10 182358

Fig. 8. SEM images of the square cavities manufactured using laser chemical machining, including the two steps: roughing and finishing (top views under $0^{\circ}$ and $60^{\circ}$ ). For captured images under $60^{\circ}$ occurring optical distortions make the back wall, on which the electron beam is focused, appear longer in comparison to the upper cavity edge.

In general, laser chemical machining shows sharp and accurate contours. The visual impressions from Figure 8 were investigated quantitatively by determining the removal depth $d_{\text {rem }}$ as well as the edge radius $r_{e}$, as depicted in Figure 9a. The required depth of $60 \mu \mathrm{m}$ was already achieved after the LCM roughing. The LCM finishing step led to an additional removal depth of about $12 \mu \mathrm{m}$. Thus, the depth of the resulting cavities ranged between $75 \mu \mathrm{m}$ and $78 \mu \mathrm{m}$, while the depth standard deviation was less than $10 \mu \mathrm{m}$ (see Fig. 9a). Using the 2D holistic approximation (see Sect. 2.4) the mean edge radii (see Fig. 9a) were determined to be $11.21 \mu \mathrm{m}$ and $18.9 \mu \mathrm{m}$ for the cavities with side lengths of $150 \mu \mathrm{m}$ and $300 \mu \mathrm{m}$, respectively. Thereby, the $r_{e}$-uncertainties were lower than $1.6 \mu \mathrm{m}$. Moreover, the LCM finishing process did not significantly increase the edge radius for both cavity sizes.

Figure 9b shows the surface quality of LCM roughened and finished cavities, which is characteristic for both cavity dimensions, in comparison to the surface of base material. The related arithmetical mean areal roughness $S a$ on the cavity ground revealed that LCM roughing is characterized by $S a>1.8 \mu \mathrm{m}$. This has been clearly reduced during the finishing step down to $0.8 \mu \mathrm{m}$. However, the microscopic images (see Fig. 9b) show that the laser-induced waviness has not been totally removed. 


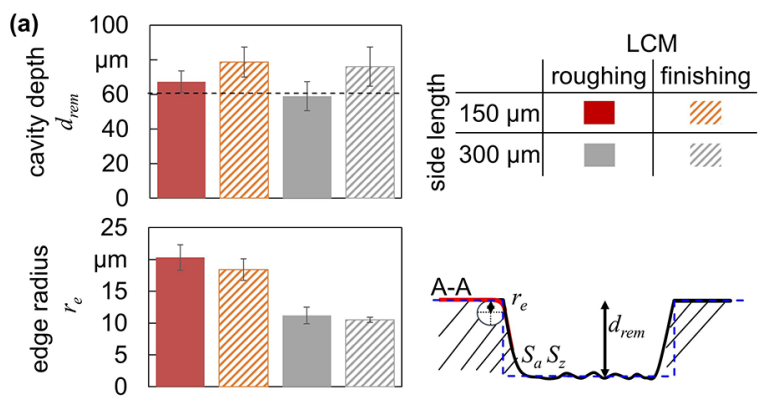

(b)

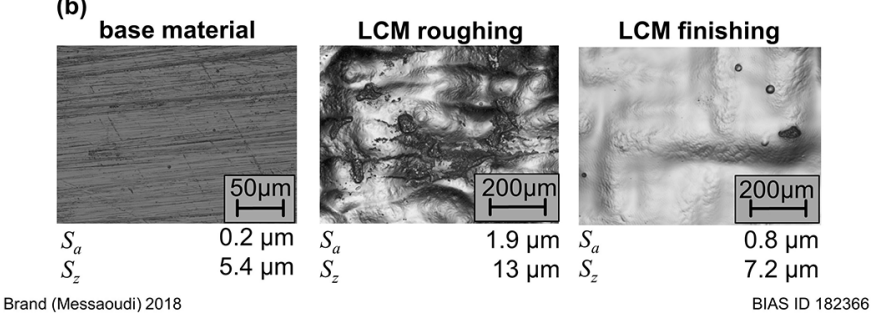

Fig. 9. Achieved (a) mean removal depths and mean edge radii of both cavity dimensions as well as (b) microscopic images of the ground surface for laser chemically roughened and finished cavities.

Table 3. Mean values of the atomic mass $\%$ of the element distribution determined from the EDS-analysis.

\begin{tabular}{llll}
\hline & $\begin{array}{l}\text { Base } \\
\text { material }\end{array}$ & $\begin{array}{l}\text { After LCM } \\
\text { roughing }\end{array}$ & $\begin{array}{l}\text { After LCM } \\
\text { finishing }\end{array}$ \\
\hline $\mathrm{Co}$ & 61.2 & 48.7 & 59.1 \\
$\mathrm{Cr}$ & 28.0 & 28.0 & 28.7 \\
$\mathrm{Mo}$ & 3.6 & 10.7 & 3.2 \\
$\mathrm{Si}$ & 1.3 & 1.4 & 1.0 \\
$\mathrm{O}$ & 2.2 & 5.0 & 3.2 \\
$\mathrm{P}$ & 0.0 & 2.1 & 0.1 \\
\hline
\end{tabular}

\subsubsection{Microstructural impact}

To examine possible thermal impacts of laser chemical machining on the surface-near layers, the chemical composition at different regions from the ground, the walls and the upper borders of selected cavities were analyzed by energy dispersive spectroscopy (EDS) and were compared with the base material. The mean values obtained from all measurements are illustrated in Table 3. Thereby a dependence of the element distribution on the machining process is observed. Co and Mo showed an inverse behavior. This is clearly visible in particular during the laser chemical roughing, in which on the one hand Co was reduced from $61.2 \%$ down to $49 \%$ and on the other hand the amount of Mo was tripled to $10.7 \%$. In addition, the laser chemical finishing results in re-setting the surface conditions of the base material and removing residues of phosphor and oxygen detected after the roughing step. Additional microscopic images of metallographic crosssections could not reveal any micro structural changes in the surface-near layers [17].

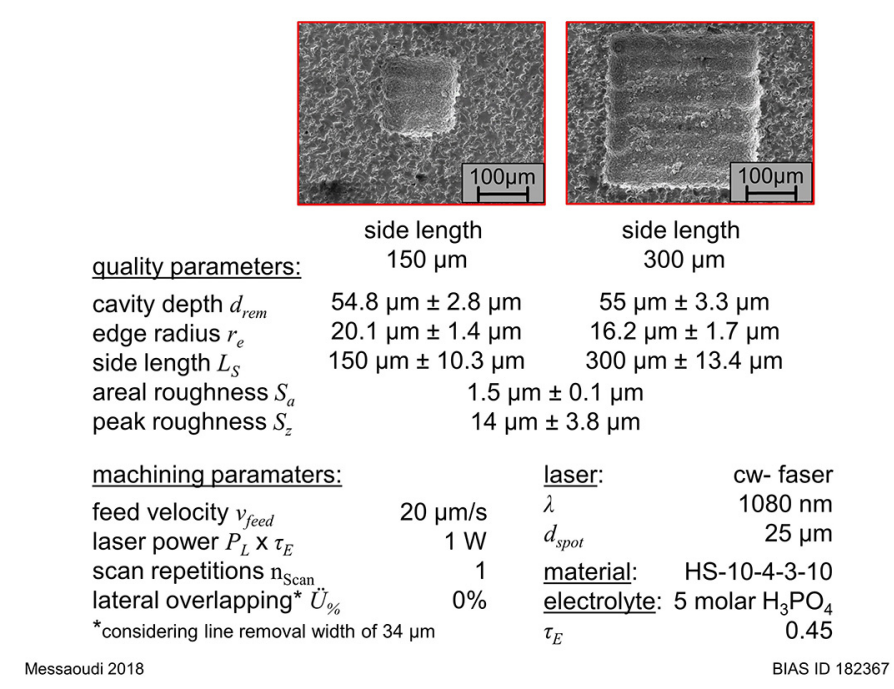

Fig. 10. SEM-images of LCM manufactured square cavities in HS10-4-3-10 within a 5 molar $\mathrm{H}_{3} \mathrm{PO}_{4}$ environment with side lengths of $150 \mu \mathrm{m}$ and $300 \mu \mathrm{m}$ as well as their related quality parameters.

\subsection{Manufacturing of square cavities in HS10-4-3-10}

\subsubsection{Geometrical properties}

As described in Section 3.3, the surface quality could not be further improved within the finishing step. Instead of a surface polishing, the arithmetical mean roughness $S a$ increased to $>2.3 \mu \mathrm{m}$. For this reason, the square cavities in HS10-4-3-10 were manufactured with a single scan repetition using the roughing parameters $P_{L} \times \tau_{E}=1 \mathrm{~W}$ and $v_{\text {feed }}=20 \mu \mathrm{m} / \mathrm{s}$.

Figure 10 shows SEM-images of the machined cavities and their related quality parameters. The machining time was kept to a minimum by applying a single repetition with a lateral overlapping of $0 \%$ taking into account the permanent background etching. This led to machining times of $37.5 \mathrm{~s}$ and $150 \mathrm{~s}$ for the manufacture of cavities with side lengths of $150 \mu \mathrm{m}$ and $300 \mu \mathrm{m}$, respectively. The cavity characterization has shown that on the one hand the removal depth amounted to $55 \mu \mathrm{m}$ in average. The maximum standard deviations of $3.3 \mu \mathrm{m}$ revealed a flat removal in the cavity ground. On the other hand, the mean edge radii ranged between $16 \mu \mathrm{m}$ and $20 \mu \mathrm{m}$ and were similar to those measured in Stellite 21. Moreover, the surface quality obtained $(S a=1.5 \mu \mathrm{m}$ and $S z=14 \mu \mathrm{m})$ is typical for the LCM roughing, as low feed velocities $\left(v_{\text {feed }}<\right.$ $50 \mu \mathrm{m} / \mathrm{s}$ ) were applied. In addition, an intensified grain boundary attack was observed due to the unequal dissolution rates of the different phases in the used electrolyte solution.

\subsubsection{Microstructural impact}

As Figure 11 shows, the chemical composition of the workpiece surface in air (base material) was similar to that in phosphoric acid environment (background etching). Only a presence of phosphor is observed during the 


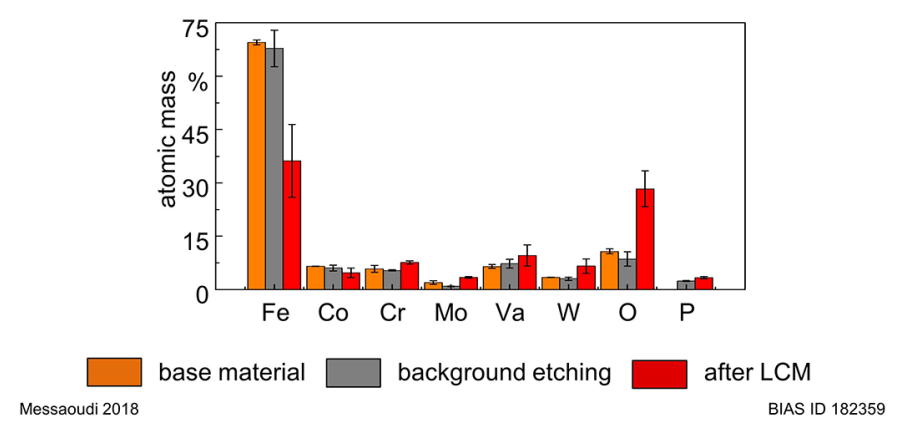

Fig. 11. Atomic mass distribution of relevant elements in HS104-3-10 determined from the EDS-analysis.

material dissolution due the formation of metallic salts. In contrast, the LCM process has significantly changed the material chemical composition. While the elements Fe and Co were preferably removed, the amount of Mo, W, Va and $\mathrm{Cr}$ increased after the LCM process. In addition to phosphor, a significant rise of oxygen was detected too. The similar was observed during the LCM-roughing of Stellite 21 in phosphoric acid environment and indicates a formation of metallic oxides.

\section{Discussion}

\subsection{Influence of self-passivation property on the machining quality}

With respect to the electrolyte solution the self-passivation of the used material is usually required in laser chemical machining. The LCM of Stellite 21 in phosphoric acid environment shows, as expected, similar behavior compared with other self-passivating materials, such as titanium [23], memory shape alloys (e.g. nickel-titanium alloys) [12] and stainless steel [24]. A detectable ( $d_{\text {rem }}>$ $0.5 \mu \mathrm{m}$ ) and disturbance-free removal took place within some $100 \mathrm{~mW}$ (between $0.55 \mathrm{~W}$ and $0.8 \mathrm{~W}$ ). This corresponds to induced surface temperatures below the electrolyte film boiling. As was demonstrated in [18], removal disturbances occur at temperatures ranging between the electrolyte boiling point and the beginning of film boiling. Their occurrence depends on the one hand on the material tendency to build up gas bubbles and on the other hand on the hydrodynamic conditions at the interaction zone [22].

In comparison, the LCM of materials without selfpassivation property within the used electrolyte, such as HS-10-4-3-10 in 5 molar $\mathrm{H}_{3} \mathrm{PO}_{4}$, showed a different removal behavior. The removal depth increases linearly with the laser power and does not show a maximum, as is observed during LCM of self-passivating materials. This can be traced back to the permanent background etching that provides a continuous removal after the laser beam passes the interaction zone and thereby removes possible occurring disturbances.

As demonstrated in [16], the etching rates over the workpiece, expect the limited laser-heated areas (some $100 \mu^{2}$ ) will not exceed the background etching rate of $2 \mathrm{~nm} / \mathrm{s}$. In comparison, the laser-induced removal velocities
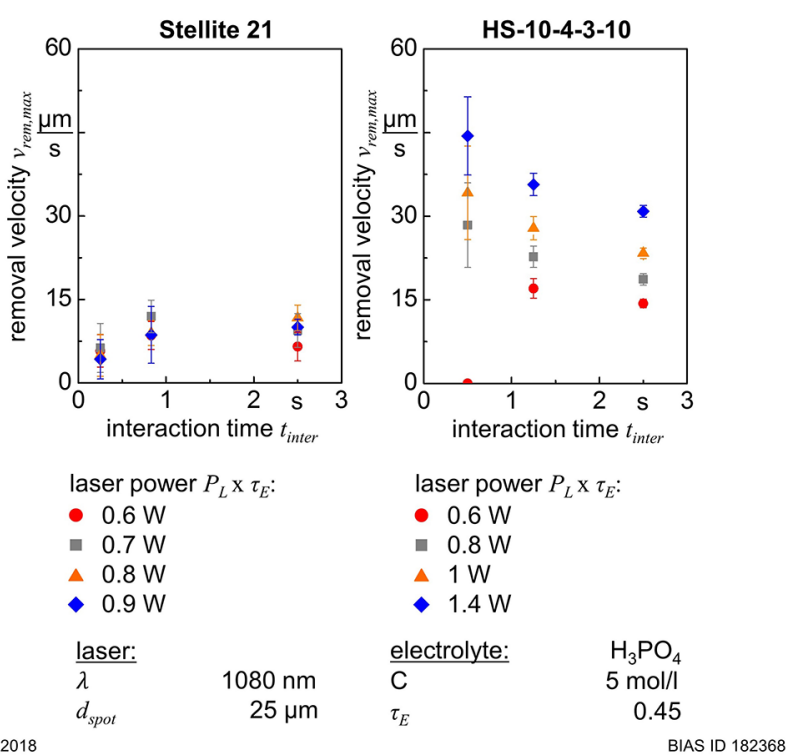

Fig. 12. Determined maximum removal velocities $v_{\text {rem,max }}$ during LCM of Stellite 21 and HS10-4-3-10 in a 5 molar phosphoric acid solution in dependence of the interaction time under different thermal loads quality parameters.

(within the interaction area) amounted to $50 \mu \mathrm{m} / \mathrm{s}(3 \mathrm{~mm} /$ min), which means up to three orders of magnitude higher removal rates than the background etching. Moreover, these velocities are about three times higher than those obtained in Stellite 21, which amounted only up to $12 \mu \mathrm{m} / \mathrm{s}$ $(0.72 \mathrm{~mm} / \mathrm{min}$ ) (see Fig. 12).

Concerning the manufacturing of the square cavities, it has been shown that a single scan repetition was sufficient to nearly achieve the required $60 \mu \mathrm{m}$ in HS10-4-3-10 due to the higher removal rate. However, the surface quality obtained after the roughing step $(S a=1.5 \mu \mathrm{m}$ and $S z=$ $14 \mu \mathrm{m}$ ) could not be improved with a subsequent finishing. In the contrary, the surface roughness has been worsened $(S a>2.2 \mu \mathrm{m}$ and $S z>25 \mu \mathrm{m})$. As the EDX-analysis in Figure 11 shows, this can be traced back to the phasedependent removal velocities as well as to an intensified grain boundary attack.

In contrast, the manufacturing strategy, consisting of roughing and finishing steps, was successfully demonstrated for the LCM of Stellite 21 in phosphoric acid solution. An enhanced material removal, which is characterized by a poor surface quality, was realized with slow scan velocities (roughing step). Besides, controllable and low removal rates have been realized with increased scan velocities and reduced laser powers. This combination was applied during the ensuing finishing step and led to an improved surface quality. The arithmetical mean roughness $S a$ was reduced from $>1.8 \mu \mathrm{m}$ down to $0.7 \mu \mathrm{m}$, while the maximum height $S z$ from $45 \mu \mathrm{m}$ was decreased down to $8 \mu \mathrm{m}$. However, surface features with spatial wavelengths $>10 \mu \mathrm{m}$ could not be efficiently removed (see Fig. 9b). Considering the micro roughness (spatial wavelengths $<5 \mu \mathrm{m}$ ), the results in [15] showed that laser chemical machining is able to achieve values down to $0.2 \mu \mathrm{m}$. The LCM-induced surface irregularities are related to two different effects. The first 
one is due to the used Gaussian laser beam profile, which results in an inhomogeneous removal even with closed hatching distance [25]. The second effect is related to the unequal chemical dissolution rates of the different elements/phases with respect to the used electrolyte solution [26] as well as the dependence of the achievable surface quality on the micro structure (grain size and element distribution) [15]. Furthermore, it has to be mentioned that the finishing step results also in removing the residues of oxygen and phosphor as well resetting the chemical composition of the base material.

Moreover, the determined edge radii ranged from $16 \mu \mathrm{m}$ to $21 \mu \mathrm{m}$ in HS10-4-3-10, while ranging between $10.5 \mu \mathrm{m}$ and $18 \mu \mathrm{m}$ in Stellite 21. The slightly higher $r_{e}$-values in HS10-4-3-10 can be traced back on the one hand to the background etching, which result in smoothing the cavity edges. On the other hand, the decreasing edge radius with increased cavity dimensions $(18 \mu \mathrm{m}$ for the smaller and $10 \mu \mathrm{m}$ for the bigger cavity size) can be explained by an increased efficiency in transporting the reaction products and exchanging fresh reactants with increased cavity size.

\subsection{Comparison of laser chemical machining with other processing methods}

\subsubsection{Removal velocities}

As already shown in Section 4.1, the LCM removal velocities $v_{\text {rem,max }}$ depend on the chemical reactivity of the material in the used electrolyte environment. For the 5 molar $\mathrm{H}_{3} \mathrm{PO}_{4}$-solution, the maximum removal velocities in Stellite 21 amounts up to $0.72 \mathrm{~mm} / \mathrm{min}$. In other selfpassivating materials, such as titanium and stainless steel (AlSI304), the removal velocities could achieve $1.2 \mathrm{~mm} /$ min [27]. In comparison, the LCM of the non-selfpassivating of HS10-4-3-10 was realized with $v_{\text {rem,max }}$ up to $3 \mathrm{~mm} / \mathrm{min}$. These determined LCM removal velocities of some $\mathrm{mm} / \mathrm{min}$ within the disturbance-free removal regime are comparable to the feed speeds usually applied in the ECM-process. Despite the much higher removal rates (some $\mathrm{mm}^{3} / \mathrm{min}$ ) that are related to the size of used electrodes, the ECM of titanium- and nickel-base for aero engine components is realized with feed velocities between $0.5 \mathrm{~mm} / \mathrm{s}$ and $1.5 \mathrm{~mm} / \mathrm{min}$, as reported by Klocke et al. [28]. Taking similar interaction zones (some $10^{4} \mu \mathrm{m}^{2}$ ), as is the case in micro-ECM, it can be stated that LCM shows a higher removal efficiency. Han et al. [29] have determined feed velocities of $0.4 \mu \mathrm{m} / \mathrm{s}$ to $1 \mu \mathrm{m} / \mathrm{s}$ in micro-ECM of micro-rods out of stainless steel (AISI304).

\subsubsection{Benchmarking with micro milling}

The machining quality of laser chemical machining has been compared in detail with micro milling in [17], where the same cavity dimensions, as depicted in Figure 1, were manufactured by micro milling in Stellite 21 using hard coated tungsten carbide ball-end mills with diameters of $0.2 \mathrm{~mm}$ and $0.1 \mathrm{~mm}$. The micro milled cavities have undergone the same characterization as the laser chemically machined ones.

Figure 13 shows SEM-images of square cavities (side length of $150 \mu \mathrm{m}$ ) manufactured with both processes. It is
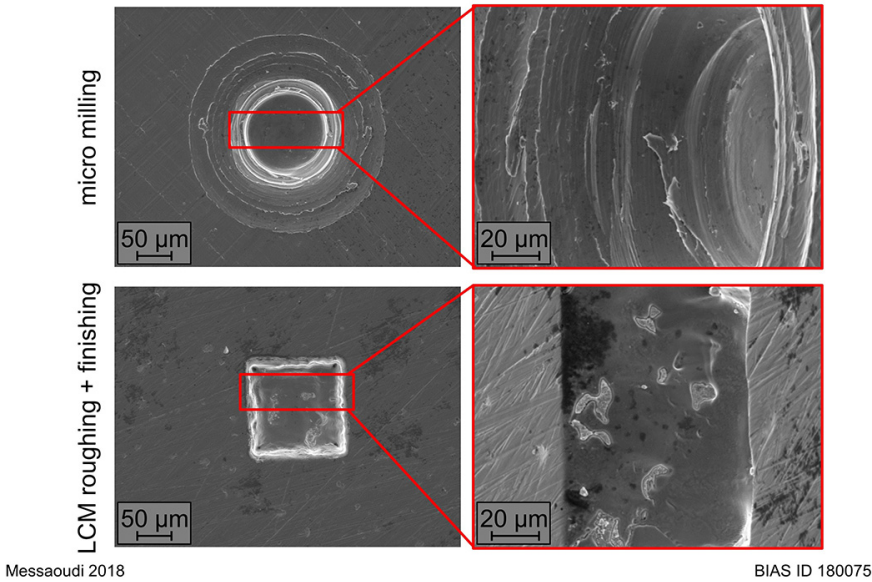

Fig. 13. Top view SEM images of a micro milled (above) and laser chemically machined (below) cavity with targeted dimensions of $(150 \times 150 \times 60) \mu^{3}$ as well as under $60^{\circ}$ magnified sections showing the cavity wall [17].

seen that the required sharp contours of the square geometry could not be realized with micro milling. The achieved edge radii $r_{e}$ were larger than those obtained with LCM due to their dependence on the diameter of the applied tool (lower $r_{e}$-limit was $50 \mu \mathrm{m}$ as the end ball mill has a diameter of $100 \mu \mathrm{m})$. The burr formation in the cavity walls, as seen in Figure 13, could be traced back on the one hand to a local undershooting of the minimum uncut chip thickness and on other hand to a ploughing of the cutting edge in the workpiece. In addition, it was found that the micro milled cavities were subject to an increased presence of oxygen. This indicated that thermal loads were applied to the workpiece due to the friction between the flank faces of the cutting edges and the workpiece material. These effects were possibly intensified with ongoing wear of the flank faces [30]. However, a negative impact on the surface near work piece material layer, such as crack induction, was not determined after the machining experiments.

In comparison, the square shape of the LCM manufactured cavities was sharper and more accurate than that of the micro milled one. This revealed that laser chemical machining (consisting of roughing and finishing steps) is more suitable for manufacturing cavities with dimensions $<200 \mu \mathrm{m}$ due to higher shape accuracy with stable mean edge radii of $(11.2 \pm 1.3) \mu \mathrm{m}$, as can be seen in Figure 13. However, the finish quality of micro milling with arithmetical mean roughness $S a$ of $0.2 \mu \mathrm{m}$ could not be achieved with laser chemical machining. Due to in-process induced waviness (at spatial wavelengths between $20 \mu \mathrm{m}$ and $100 \mu \mathrm{m}$ ), the surface quality could be only improved from $S a>2 \mu \mathrm{m}$ down to $0.7 \mu \mathrm{m}$. Further, the metallographic analysis of the surface-near layers reveals that both manufacturing processes ensure gentle machining without any noticeable micro structural impact.

In view of machining time, micro milling is more efficient than laser chemical machining, e.g., $5 \mathrm{~min}$ and $200 \mathrm{~min}$ were needed for the machining of one cavity of $(300 \times 300 \times 60) \mu^{3}$, using micro milling and LCM, 
Table 4. Summary of the quality characteristics of laser chemical machining in comparison with micro milling [17].

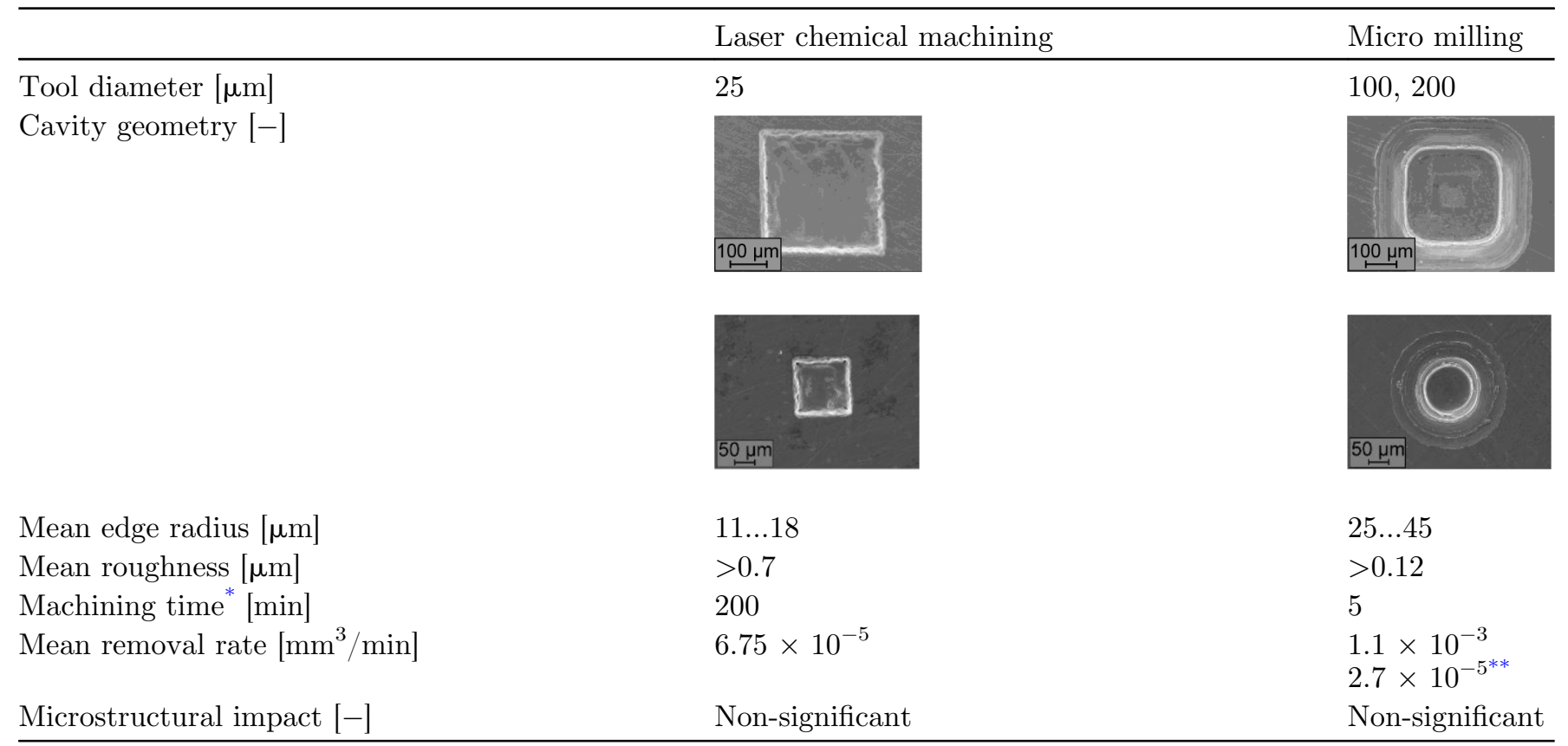

${ }^{*}$ For cavity dimensions of $(300 \times 300 \times 60) \mu \mathrm{m}^{3}$.

** Considering equal interaction areas (similar to those of LCM).

respectively. However, when considering the tool interaction area $\left(31.5 \times 10^{3} \mu \mathrm{m}^{2}\right.$ for the $100 \mu \mathrm{m}$ ball-end mill and $2 \times 10^{3} \mu^{2}$ for the laser beam), which is about 16 times larger for micro milling, the LCM removal rates were close to those of micro milling. With regard to the tool area, the average removal rates within the applied machining conditions amounted to $2.7 \times 10^{-5} \mathrm{~mm}^{3} / \mathrm{min}$ for $\mathrm{LCM}$ and $6.75 \times 10^{-5} \mathrm{~mm}^{3} / \mathrm{min}$ for micro milling.

Looking at Table 4, which summarizes the main benchmarking results between laser chemical machining and micro milling, it can be ascertained that laser chemical machining offers higher accessibility and accuracy in the dimension range of $<200 \mu \mathrm{m}$. Moreover, LCM offers the opportunity to use one single tool, the laser beam, that can be varied in its properties (spot size, intensity profile and $\mathrm{cw}$ /pulsed mode) much easier compared to micro milling, which necessitates a tool change within the process. Nevertheless, it is still challenging to minimize the waviness effect during the roughing procedure. In contrast, micro milling is predestined for the machining of structures with dimensions $>500 \mu \mathrm{m}$. Further, it is still providing the better surface finish as well as the more homogeneous material removal. Therefore, a combination of both methods to avoid burr formation and to realize better wall curvature is an approach to follow towards the manufacturing of highly accurate micro metallic parts. In view of micro forming processes, a promising application is the high-precision manufacturing of metallic dies, used for micro deep drawing or micro stamping. Here, micro milling can be used for a rough clearing of the die geometry and a high-finish of the ground surface. Subsequently, LCM can be applied for a precise contouring of the die edges. This additional finishing step includes the clearing of possible burr formed during micro milling and the sharpening of the edge radii.

\section{Conclusions}

The laser chemical machining (LCM) of tool steels was investigated in dependence of their passivation property within a 5 molar phosphoric acid environment. For the selfpassivating Cobalt-Chrome alloy Stellite 21 the removal velocities achieved $12 \mu \mathrm{m} / \mathrm{s}$. Based on the machining strategy, consisting of roughing and finishing steps, the surface roughness Sa could be reduced from $>2 \mu \mathrm{m}$ down to $0.8 \mu \mathrm{m}$. In contrast, the LCM in the non-passivating highspeed steel HS10-4-3-10 was realized with up $50 \mu \mathrm{m} / \mathrm{s}$, considering background etching rates of up to $2 \mathrm{~nm} / \mathrm{s}$ at room temperature.

Despite the different removal behaviors, LCM of tool steels provides high shape and dimensional accuracy. In this contribution, sharp edge contours with mean edge radii ranging between $10 \mu \mathrm{m}$ and $20 \mu \mathrm{m}$ were achieved. In comparison with micro milling, LCM is particularly suited for the manufacture of micro cavities with dimensions $<200 \mu \mathrm{m}$. However, the induced surface waviness presents a limiting factor that affects the surface quality. To further improve the process competitiveness, future works should focus on developing suitable scan strategies to reduce both the surface waviness and roughness.

The authors would like to thank the German Research Foundation (Deutsche Forschungsgemeinschaft "DFG") for funding this work within the sub-projects A5 "Laser Contour" 
and B5 "Reliable Processes" of the Collaborative Research Centre 747 "Micro Cold Forming - Processes, Characterisation, Optimisation" at the University of Bremen. Furthermore, the authors would like to thank Mr. Florian Böhmermann, Dr.-Ing. Oltmann Riemer and Mr. Christian Rösner for their cooperation during the benchmarking study with micro milling. Last but not least greatest thanks, too, to Mrs. Denise Loske for her support during the metallographic investigations.

\section{References}

1. M. Geiger, F. Vollertsen, R. Kals, CIRP Ann. - Manuf. Technol. 45 (1996) 277-282

2. M. Geiger, M. Kleiner, R. Eckstein, N. Tiesler, U. Engel, CIRP Ann. - Manuf. Technol. 50 (2001) 445-462

3. E. Brinksmeier, A. Schulz, Micro metal forming, Springer Verlag, 2013, pp. 204-223

4. F. Vollertsen, D. Biermann, H.N. Hansen, I.S. Jawahir, K. Kuzman, CIRP Ann. - Manuf. Technol. 58 (2009) 566-587

5. D. Dornfeld, S. Min, Y. Takeuchi, CIRP Ann. - Manuf. Technol. 55 (2006) 745-768

6. M.A. Câmara, J.C. Campos Rubio, A.M. Abrão, J.P. Davim, J. Mat. Sci. Technol. 28 (2012) 673-685

7. M. Manjaiah, S. Narendranath, S. Basavarajappa, Trans. Nonferrous Met. Soc. China 24 (2014) 12-21

8. M. Weikert, C. Fohl, F. Dausinger, T. Abeln, SPIE 5063 (2003) 208-213

9. R.J. Leese, A. Ivanov, Adv. Mech. Eng. 8 (2016) 1-13

10. A. Stephen, T. Lilienkamp, S. Metev, G. Sepold, Proc. 1st Int. Conf. EUSPEN, Shaker Verlag (1999) pp. 20-23

11. D. Bäuerle, Laser Processing and Chemistry, Springer Verlag, 2011

12. A. Stephen, F. Vollertsen, CIRP Ann. - Manuf. Technol. 59 (2010) 251-254
13. H. Messaoudi, O. Hauser A. Matson, S. Mehrafsun, F. Vollertsen, Proc. 8th. Kolloquium Mikroproduktion (2017) pp. $171-178$

14. P. Zhang, A. von Freyberg, A. Fischer, Int. J. Adv. Manuf. Tech. 93 (2017) 3693-3703

15. S. Eckert, A. Köhnsen, F. Vollertsen, Proc. Laser in Manufacturing Conference (LIM2017) (2017), pp. 1-8

16. H. Messaoudi, D. Brand, F. Vollertsen, Proc. 14th international Symposium on Electrochemical Machining INSECT2018 (2018), pp. 47-53

17. H. Messaoudi, F. Böhmermann, M. Mikulewitsch, A. von Freyberg, A. Fischer, O. Riemer, F. Vollertsen, MATEC Web Conf. 190 (2018) 15010

18. H. Messaoudi, S. Eckert, F. Vollertsen, Mater. Sci. Appl. 8 (2017) 685-707

19. A. von Freyberg, A. Fischer, Precis. Eng. 54 (2018) 396-402

20. K. Lübke, Z. Sun, G. Goch, CIRP Ann. - Manuf. Technol. 61 (2012) 499-502

21. J.M. Linares, G. Goch, A. Forbes, J.M. Sprauel, A. Clément, F. Haertig, W. Gao, CIRP Ann. - Manuf. Technol. 67 (2018) 815-838

22. S. Mehrafsun, H. Messaoudi, J. Manuf. Mater. Proc. 2 (2018) 54

23. O. Hauser, S. Mehrafsun, F. Vollertsen, Appl. Mech. Mater. 794 (2015) 262-269

24. R. Nowak, S. Metev, Appl. Phys. A 63 (1996) 133-138

25. O. Hauser, S. Mehrafsun, F. Vollertsen, 7th Kolloquium Mikroproduktion (2015) 8-14

26. F. Klocke, S. Harst, F. Karges, M. Zeis, A. Klink, CIRP Conf. Model. Mach. Oper. 58 (2017) 169-174

27. H. Messaoudi, M. Mikulewitsch, A. Fischer, G. Goch, F. Vollertsen, in Micro cold forming, Lecture Notes in Production, eds. F. Vollertsen, S. Friedrich, C. Thomy, Springer International Publishing AG Cham/ Switzerland (2019) Sect. 4.3

28. F. Klocke, M. Zeis, A. Klink, D. Voselovac, Procedia CIRP 2 (2013) 98-101

29. W. Han, M. Kuneida, Procedia CIRP 42 (2016) 819-824

30. H.K. Tönshoff, H.-G. Wobker, D. Brandt, HörtereiTechnische Mitteilungen-HTM 50 (1995) 176-181

Cite this article as: Hamza Messaoudi, Merlin Mikulewitsch, Daniel Brand, Axel von Freyberg, Andreas Fischer, Removal behavior and output quality for laser chemical machining of tool steels, Manufacturing Rev. 6, 13 (2019) 